\title{
Management issues for women with epilepsy
}

\section{A review of the literature}

\author{
C.A. Zahn, MD, MHSc; M.J. Morrell, MD; S.D. Collins, MD, PhD; D.M. Labiner, MD; \\ and M.S. Yerby, MD, MPH
}

\begin{abstract}
Article abstract-Objective: A review of literature referable to management issues for women with epilepsy (WWE) was undertaken for the development of a practice parameter. Background: Epilepsy is a common neurologic condition with gender-related management implications. Although reviews of this topic often focus on pregnancy-related issues for WWE, specific health concerns for WWE are present throughout all phases of reproductive life. Methods: An OVID MEDLINE literature search was conducted for 1965 to 1997 using the following key words/phrases and cross referencing: epilepsy/ seizures and pregnancy, anticonvulsants, antiepileptic drugs (AEDs), teratogenesis, oral contraceptives, birth defects, folate/folic acid, vitamin K, metabolic bone disease, and breast-feeding. Results: Pregnancy outcome literature for WWE spans several decades. Methodology varies and interpretation is complicated by modern management strategies. Contributions of socioeconomic factors, AEDs, maternal epilepsy, and seizures during pregnancy to adverse pregnancy outcomes have not been clearly delineated. There is a biologic basis for recommendations concerning contraception, folate supplementation, vitamin $\mathrm{K}$ use in pregnancy, breast-feeding, metabolic bone disease, catamenial epilepsy, and reproductive endocrine disorders, but no outcome studies afford a strong evidence base for practice recommendation. Conclusions: WWE face health issues for which there is no available outcome literature to guide decision making. The urgent need for studies in many of these areas is highlighted by expanded treatment options with new AEDs and epilepsy surgery.
\end{abstract}

Epilepsy is a common neurologic condition. Recently reported epidemiologic data indicate a cumulative lifetime risk of any convulsive disorder as being over $11 \%$, and an epilepsy prevalence of 6.8 per 1,000 population. ${ }^{1}$ Epilepsy has special implications for women's health, and specific management strategies are required to surmount problems posed by reproductive endocrine disorders, pregnancy, and the effects of changing hormonal status through reproductive life phases for women with epilepsy (WWE).

The results of two recent surveys suggest that specialists providing care for WWE are not optimally informed regarding health issues for this patient population. ${ }^{2,3}$ This is also likely to be true of primary care physicians, who often provide principal care for people with epilepsy. As gender-specific health issues span the entire adult life of the WWE, a longitudinal relationship with an experienced provider will facilitate comprehensive counseling, successful pre-emptive intervention, and effective specialty consultation for epilepsy-associated health concerns.
Gender-related management questions for WWE are addressed in this review, which was done in conjunction with the development of a practice parameter by the American Academy of Neurology's Quality Standards Subcommittee. ${ }^{4}$

Management issues for WWE during reproductive years. Ovarian hormone influences. Experimental epilepsy models have repeatedly demonstrated a relationship between ovarian hormones and neuronal excitability. ${ }^{5-8}$ In animal models, estrogens lower seizure threshold and progestins are seizure protective. Estrogen administered intravenously to a small series of patients has been shown to increase epileptiform discharges ${ }^{9}$ and progesterone to reduce spike frequency in some WWE. ${ }^{10}$

Many WWE report variable seizure frequency in relation to their menstrual cycle. The true frequency of menstrual exacerbations of seizures (catamenial epilepsy) is unclear, partly due to variability in definition. Duncan et al. defined catamenial seizures

See also pages 944 and 1039

From the Division of Neurology (Dr. Zahn), The Toronto Hospital and The University of Toronto, Ontario, Canada; the Stanford Comprehensive Epilepsy Center (Dr. Morrell), Stanford University School of Medicine, Stanford, CA; the Comprehensive Epilepsy Center (Dr. Collins), Case Western Reserve University, Cleveland, OH; the Department of Neurology (Dr. Labiner), Arizona. Health Sciences Center, Tucson, AZ; and Oregon Health Sciences University (Dr. Yerby), Portland, OR. Received November 17, 1997. Accepted in final form August 1, 1998.

Address correspondence and reprint requests to Dr. Catherine Zahn, The Toronto Hospital, Western Division, 8 Edith Cavell-034, 399 Bathurst Street, Toronto, Ontario M5T 2S8, Canada; e-mail: czahn@torhosp.toronto.on.ca 
strictly as at least $75 \%$ of seizures occurring within 4 days preceding and 6 days after the onset of menstruation. Only $12.5 \%$ of 40 women studied met this criteria for catamenial seizures. ${ }^{11}$ Reports using more liberal criteria, including women who document a greater than average or increased frequency of seizures perimenstrually, suggest a catamenial seizure exacerbation in as many as $78 \%$ of women. ${ }^{12,13}$

The propensity for increased seizure occurrence appears highest just before and during menstruation and at the time of ovulation. Physiologically, this timing corresponds to periods of relatively high estrogen and low progesterone levels. ${ }^{9,14}$ The phenomenon may be more marked in anovulatory cycles in which the estrogen level remains high in the absence of the normal progesterone rise with ovulation. Cummings et al. reported over one-third of women with temporal lobe seizures as having an anovulatory cycle over a time frame of three cycles compared with less than $10 \%$ of control women or women with primarily generalized epilepsy. ${ }^{15}$ Antiepileptic drug (AED) supplementation and a variety of hormone manipulation strategies have been reported in small, uncontrolled case series for women experiencing catamenial changes in seizure frequency.

The expression of seizures in the peri and postmenopausal woman has not been well studied. The effect of hormone replacement on seizure control for postmenopausal women also requires evaluation.

Fertility. Menstrual cycle disturbances, hypergonadotrophic and hypogonadotrophic hypogonadism, polycystic ovaries, sexual dysfunction, and reduced fertility are documented problems for WWE. ${ }^{15-18}$ Fertility may be as low as two-thirds of that expected in the general population. ${ }^{19,20}$ Menstrual dysfunction and reproductive endocrine disorders are seen with increased frequency, compared with general population figures, in women with temporal lobe epilepsy, with or without AED treatment. ${ }^{21}$ Abnormalities of physiologic sexual arousal may lead to sexual dysfunction in both men and women with epilepsy. ${ }^{22,23}$ These disorders have been postulated to be secondary to the effects of seizures on prolactin, gonadotropin, and sex steroid hormone levels, although AEDs and psychosocial and socioeconomic factors may have a contributing role. Obstetric complications may be implicated in reduced fertility for WWE. These are discussed in the context of WWE during pregnancy.

Contraception. The known effects of ovarian sex steroid hormones on neuronal excitability suggest that the use of hormonal contraception has the potential to alter seizure control in WWE. There have, however, been no reports of worsening of seizure control for WWE who use hormonal contraception.

Case reports of hormonal contraceptive failure with AED use began to appear in the early 1970s. The AEDs phenobarbital, primidone, phenytoin, carbamazepine, and topiramate are inducers of the hepatic cytochrome $\mathrm{P} 450$ system of mixed function oxidases. They have been demonstrated to increase steroid hormone binding globulins with a reduction in free hormone levels. The use of these AEDs is associated with a reduction of exogenous estradiol and progesterone levels in WWE using hormonal contraception. ${ }^{24-26}$ This may result in failure of hormonal contraception. Breakthrough bleeding may occur, although ovulation and pregnancy can result without this warning. Valproic acid and felbamate inhibit the hepatic microsomal enzyme system; other newer AEDs, including gabapentin, lamotrigine, tiagabine, and vigabatrin, appear to have no significant effect.

Neither levonorgestrel implants nor IM medroxyprogesterone have been shown to be superior to oral contraceptives in WWE using enzyme-inducing AEDs. Levonorgestrel is a progestin-only formulation with reduced efficacy in this setting. ${ }^{27} \mathrm{IM}$ medroxyprogesterone delivers much higher dosages of progestin for contraception but has not yet been evaluated for effectiveness in WWE.

Metabolic bone disease. Metabolic bone disease is a health concern for all women. The concern is potentially greater for WWE who have been exposed to AEDs. AEDs are believed to be associated with disorders of bone metabolism with evidence of reduced levels of active vitamin $\mathrm{D}$, osteomalacia, osteoporosis, and fractures reported in patients exposed to AEDs. ${ }^{28-30}$ Theories of pathogenesis include increased metabolism of vitamin $\mathrm{D}$ to inactive metabolites by AED-induced hepatic enzymes, AED interference with intestinal absorption of calcium, and a direct AED effect on bone cell function through inhibition of cellular response to parathyroid hormone (PTH). Methodologic flaws of available studies include small sample size, poorly matched controls, failure to control for diet and activity, and inadequate measures of bone health. It is not clear, therefore, whether AED exposure, over the short or long term, has an additional clinically significant impact on the problem of metabolic bone disease in women.

Pregnancy-related management issues for WWE. Folic acid supplementation. Low serum and erythrocyte folate levels have been associated with spontaneous abortion and fetal malformations in animal models and in humans. Treatment with some AEDs, including phenytoin, carbamazepine, and barbiturates, can impair folate absorption. Maternal valproic acid and carbamazepine use have been associated with increased risk of neural tube defects in infants of WWE at 1 to $2 \%$ and 0.5 to $1 \%$, respectively. ${ }^{31-34}$ Although valproic acid does not produce folate deficiency, it may interfere with the production of folinic acid by inhibiting glutamate formyl transferase. There is, therefore, a biologic basis for the recommendation of prepregnancy and early pregnancy folic acid use for WWE during reproductive years, but very little information in the literature concerning dietary folate supplementation specifically referable to WWE who take AEDs.

Observational studies ${ }^{35}$ and randomized controlled trials $^{36,37}$ have confirmed that maternal dietary sup- 
plementation with folic acid reduces the risk of neural tube defects for the infants of women in the general population. The optimal dosage is unclear, as study supplementation has varied between 0.36 and $5 \mathrm{mg} / \mathrm{day}$. The Centers for Disease Control and Prevention recommend a dosage of $0.4 \mathrm{mg} / \mathrm{day}$ for primary prevention of neural tube defects in all women of childbearing age..$^{38}$ One case control study has shown a graded effect of folate deficiency in the occurrence of neural tube defects. ${ }^{39}$ Although levels lower than $340 \mathrm{nmol} / \mathrm{L}$ produced the highest risk, the protective effect of folate is maximal with higher levels. The Canadian College of Medical Geneticists recommends prepregnancy and pregnancy folic acid supplementation at a dosage of up to $5 \mathrm{mg} /$ day for women who have had a child with a neural tube defect to prevent recurrence. ${ }^{40}$

As many as half of recognized pregnancies in the United States are unplanned and many women with planned pregnancies have not consulted a health care provider before pregnancy. ${ }^{41}$ These statistics emphasize the need for early counseling of WWE during reproductive years and suggest that the general recommendation for dietary folate supplementation of all women during reproductive years be reinforced for WWE. The mechanisms by which WWE are at risk for having children with neural tube defects may differ from those of women without epilepsy. Outcome studies will be necessary to determine whether folate supplementation reduces the risk for WWE of having children with neural tube or other birth defects.

Obstetric outcomes. WWE are at increased risk for pregnancy complications. Socioeconomic factors may play a significant role, as some patients with epilepsy lack adequate resources for prenatal care and optimal diet or vitamin supplementation during pregnancy. Obstetric complications that have been reported to occur with increased frequency in WWE in various surveys include vaginal bleeding, hyperemesis gravidarium, ectopic pregnancy, spontaneous abortion, premature labor and preterm delivery, forceps or vacuum assisted delivery, cesarean section, stillbirth, and neonatal death. The adverse obstetric outcomes reported most consistently as increased for WWE are stillbirth and neonatal death. ${ }^{42,43}$ One study suggests that there has been a decline in perinatal deaths with current seizure management patterns. The rate for WWE in a 1977 to 1981 cohort was $4.7 \%$ (control, $1.5 \%$ ) with the rate decreasing in the 1987 to 1991 cohort to $2.1 \%$ (control, $0.9 \%)^{44}$ Literature limitations include the use of pregnancy registry data for controls and failure to account for important variables such a socioeconomic status, AED use, and seizures during pregnancy. Available information does not permit specific recommendations regarding management strategies for prevention of obstetric complications for WWE.

Seizure control during pregnancy. The potential for change in seizure frequency for WWE during pregnancy has been documented in reports dating back to the turn of the century. An increased risk of seizures is present, probably for the minority of WWE, throughout pregnancy, including labor and delivery. Studies of the natural history of epilepsy during pregnancy have yielded a wide range of results. The methodology of the studies is variable. In some, it is unclear how the cohort was acquired or in what manner prepregnancy seizure frequencies were determined. Studies often evaluate prepregnancy seizure frequency retrospectively with pregnancy frequency measured prospectively. The triggers for AED dosage changes during pregnancy (reduced serum levels, seizure occurrence) are also unclear in most studies. Three prospective studies performed over the last 15 years report 0 to $37 \%$ of pregnancies resulting in an increase in maternal seizure frequency. ${ }^{45-47}$ In the most recent report, a prospective, population-based study of 70 WWE (93 pregnancies), Tomson et al. found unaltered seizure frequency in $61 \%$ of patients, improvement in $24 \%$, and worsening in only $15 \% .{ }^{47}$ Most patients were attending a neurologic clinic before pregnancy with case records documenting prepregnancy seizure frequency. This study failed to demonstrate a relation between AED plasma concentrations and clinical effects. Although greater prepregnancy seizure frequency has been described as a predictor of increased seizures during pregnancy, ${ }^{48}$ this has not been demonstrated in recent studies. In one study, medication noncompliance occurred in $68 \%$ of those WWE with worsened seizure control. ${ }^{45}$

Avoidance of seizures during pregnancy is desirable for psychosocial and socioeconomic reasons as well as for the physical well-being of WWE. Potential mechanisms for fetal injury after an isolated generalized seizure include physical damage due to maternal abdominal trauma as well as hypoxic-ischemic injury due to decreased placental perfusion or maternal hypoxia. Sustained changes in fetal heart rate have been documented during maternal generalized seizures. ${ }^{49}$ There are rare case reports of intrauterine death after single seizures. ${ }^{50}$ The effects of partial complex seizures and absence seizures on the fetus are unknown and the potential long-term effects of an isolated tonic-clonic seizure on the cognitive development of the fetus have not been studied.

Regular monitoring of AED levels during pregnancy is usually recommended by epilepsy experts, although caution in interpretation of results is necessary. Many studies have demonstrated a reduction in total AED plasma levels during pregnancy with less marked reduction in non-protein-bound concentrations and variable correlation with changes in seizure control. ${ }^{47,51}$ Total AED measurements do not reflect the fact that, as pregnancy progresses, there is a reduction in the protein-bound fraction of AEDs. Non-protein-bound AED levels will most accurately portray the CNS level of AEDs, especially those that are highly or moderately protein-bound such as phenytoin and valproate. The physiologic changes of pregnancy are reversed quickly in the postpartum 
period. If AED dosage increases have been made during pregnancy, levels may increase after delivery, producing toxicity.

$A E D$ teratogenesis. Congenital malformations are physical defects that cause a significant functional disturbance and require medical or surgical intervention. Anomalies are defined as minor deviations from normal morphology. Both patterns of congenital abnormalities are seen with increased frequency in infants born to WWE. There are no randomized, controlled trials of AEDs addressing these adverse pregnancy outcomes in women during reproductive years. Observational studies reporting pregnancy outcomes for WWE suffer from lack of control for variables such as AED number, type, dosage, or serum level; seizures during pregnancy; hereditary factors; and parental socioeconomic status or intelligence quotient (IQ).

Congenital malformations. Isolated case reports and small case series of congenital malformations in infants born to WWE began to appear in the literature in the early 1960s. In 1972, Speidel and Meadow published a retrospective survey identifying a significant increase in malformation rates of infants of WWE treated with AEDs compared with infants of a control group. ${ }^{52}$ Increased rates of congenital malformations in infants of WWE have been documented repeatedly in observational studies over the last 25 years. Despite literature shortcomings, reports with controls appearing since 1972 have been consistent in documenting a malformation rate in infants born to WWE taking AEDs greater than that of the control population.

Specific studies provide insights into the risks for malformations in infants of WWE and support a role of AEDs in their pathogenesis. Nakane et al. reported an $11.5 \%$ malformation rate for infants born to medicated WWE, compared with $2.3 \%$ in nonmedicated mothers. ${ }^{53}$ In this study, infants of WWE who took three or more AEDs were at highest risk. Lindhout et al.'s report also supports increased risk with polytherapy. ${ }^{54}$ Kelly et al.'s review of children born to WWE identified $4 \%$ with major malformations. ${ }^{55}$ Three children with malformations were siblings, suggesting a genetic contribution. This study was characterized by patients of low socioeconomic status, highlighting the potential role of environmental factors, although the population also had a high seizure frequency and rate of polytherapy. Kaneko et al. reported a malformation rate of $6.5 \%$ in women receiving one $\mathrm{AED}$ and $15.6 \%$ in those taking multiple AEDs. ${ }^{56}$ Battino et al. identified malformations in $9.1 \%$ of infants compared with a population rate of $2.27 \% .^{57}$ In the group of patients treated with valproic acid, first trimester maternal serum levels were higher in those with malformed infants than in those with normal infants, suggesting a graded effect of AEDs in the production of malformations.

Two studies have reported outcomes for infants born in the last 10 years. Infants of WWE remain at risk despite changing management patterns. Jick and Terris reported a $3.4 \%$ malformation rate for infants of treated WWE with a control rate of $1 \% .^{58}$ Waters et al. reported a $10.7 \%$ rate of adverse outcomes compared with $3.4 \%$ in controls, but included neonatal death and major and minor malformations. ${ }^{59}$ The pattern of birth defects in the offspring of WWE may be changing with newer management strategies. King et al. compared a 1967 to 1980 cohort with a 1981 to 1992 cohort. ${ }^{60}$ Results indicated increased risk for orofacial clefts in the earlier group with a trend toward neural tube defects in the latter. This information may reflect increasing use of valproic acid and carbamazepine, which have been implicated in the development of neural tube defects in infants of WWE. ${ }^{31-34}$

Studies also have examined seizure occurrence during pregnancy. Seizures during pregnancy are not linked to increased risk for malformations in infants of WWE in several major studies. ${ }^{53,54,56,57,59}$ An exception is Lindhout et al.'s report of a $12.3 \%$ malformation rate in WWE experiencing first trimester seizures compared with $4 \%$ in women without first trimester seizures. ${ }^{61}$

Congenital anomalies. Specific AED-related fetal syndromes have been suggested in relation to trimethadione, primidone, phenobarbital, phenytoin, benzodiazepines, valproic acid, and carbamazepine. Components of these syndromes have included minor craniofacial and digital anomalies, growth retardation, and developmental delay. Craniofacial defects and nail hypoplasia were described by Jones et al. in children of WWE treated with carbamazepine, alone and in combination. ${ }^{62}$ The authors point out a similarity between the anomalies seen and those reported to represent the fetal hydantoin syndrome. A prospective study with controls was carried out by Gaily et al. to evaluate minor anomalies in the children of WWE. ${ }^{63} \mathrm{~A}$ total of 121 children were evaluated blindly for the typical facial and digital abnormalities previously described as comprising the fetal hydantoin syndrome. Anomalies were seen with increased frequency in the children of WWE, but a pattern specific to those exposed to phenytoin was not observed. Mothers with epilepsy had an increase in anomalies when compared with controls. Nulman et al. reported a twofold increase in anomalies in children of WWE treated with phenytoin and carbamazepine, but also in the children of untreated WWE. ${ }^{64}$ Steegers-Theunissen et al. studied preconceptionally recruited WWE and controls in a prospective multicenter study. ${ }^{65}$ Infants of the cohort of WWE demonstrated a twofold increase in minor malformations and a $29 \%$ risk of adverse pregnancy outcomes compared with controls.

Thus, whereas case reports and small series initially suggested drug-specific syndromes and larger studies have confirmed the increased risk for congenital anomalies in infants of WWE, there is a great deal of overlap in the described dysmorphisms. Specific syndromes are no longer accepted, and the broader term, fetal AED syndrome, is more appropri- 
ate, although maternal epilepsy and hereditary factors appear to have a contributing role.

Developmental delay. Studies of cognitive development and intelligence of infants born to WWE also have serious limitations. Long-term follow-up is lacking. Many have failed to control for type and timing of AED exposure, compliance with medication regimen, frequency and timing of seizures during pregnancy, socioeconomic status, and parental intelligence level. Gaily et al.'s population-based study found the rate of mental retardation in children of WWE to be equal to that in the general population. ${ }^{66}$ Although mean IQ was significantly lower in the children of WWE, this was not clearly related to AED exposure. Nelson and Ellenberg reported children of WWE to be twice as likely to have decreased head circumference and low IQ as controls but also found this to be independent of AED exposure. ${ }^{42}$ Scolnik et al. found children prenatally exposed to phenytoin to have IQ levels significantly lower than controls. ${ }^{67}$ This was not seen in children exposed to carbamazepine, although many mothers were taking this drug for indications other than epilepsy, AED levels were low, and mothers in this group had higher IQ than mothers taking phenytoin. Losche et al. found a significant difference in psychological testing scores between children of WWE and controls. ${ }^{8}$ Parental IQ was not reported but lower socioeconomic status was a strong predictor of lowered scores. These studies indicate a risk for impaired cognitive development in the offspring of WWE. It is not possible, however, to ascertain reliably the contributions of heredity, maternal epilepsy or seizures during pregnancy, AEDs, or socioeconomic status given the limitations of the current literature.

Pathogenesis. Whereas the observed increase in congenital malformations and anomalies in the infants of WWE may be multifactorial, several lines of evidence implicate AEDs as a major cause. Malformation rates are higher in the infants of WWE taking AEDs than in those of untreated WWE. ${ }^{52,53}$ Infants of mothers taking polytherapy are at higher risk of malformations. ${ }^{53,54,56}$ Most investigators have not identified an association of maternal seizures during pregnancy with malformations. ${ }^{53,54,56,57,59}$ Higher mean AED concentrations are associated with increased malformation risk. ${ }^{57}$ All of the commonly used AEDs have been associated with an increased risk for malformations and anomalies. The teratogenic potential of AEDs introduced in the last few years, including gabapentin, felbamate, lamotrigine, tiagabine, topiramate, and vigabatrin, remains to be delineated. Reports of pregnancy outcomes in WWE taking these medications have been in the context of polytherapy.

Fetal accumulation of toxic intermediary AED metabolites, induction of folate deficiency, and predisposing genetic factors are proposed mechanisms for AED teratogenesis. Several AEDs are metabolized to arene oxide intermediates by the hepatic cytochrome P450 enzyme system. These intermediary metabo- lites are highly reactive. They are postulated to bind to embryonic macromolecules, disrupting normal developmental processes. The enzyme epoxide hydrolase metabolizes the biologically active epoxide metabolites of AEDs to compounds that are less toxic. ${ }^{54}$ Experimental observations have suggested a genetic defect in the detoxification of potentially teratogenic AED metabolites by epoxide hydrolase. Inhibition or deficiency of this enzyme may place the embryo at increased risk for maldevelopment. Lymphocytes of infants of WWE who had been exposed to phenytoin in utero have been studied in an in vitro drug metabolizing system. ${ }^{69}$ In 14 of 24 cases, an increase in cell death was associated with an increase in phenytoin metabolites. A positive result to the in vitro challenge was strongly correlated with major malformations. Measurement of epoxide hydrolase activity in amniocytes has also been carried out experimentally. ${ }^{70}$ Reduced levels of enzyme activity were correlated with the occurrence of congenital anomalies and hypotonia.

Risk reduction. Although studies reporting rates of congenital malformations in the offspring of WWE are flawed by current methodologic standards, the volume of evidence accumulated to date strongly supports the assertion that risk is higher for infants of treated WWE than for infants of women in the general population. Studies with controls report risk for congenital malformations as high as $18.6 \% .^{71}$ Overall, these reports indicate a rate of 1.5 to 3 times that of their control population. Risk for congenital anomalies and developmental delay is also increased, but available studies do not provide sufficiently robust data to define the degree. Data regarding a selective benefit of one AED over another are unavailable. It has become common practice to quote a risk for major malformations of 4 to $6 \%$ to WWE. This approach may be too simplistic, however, as the risk for all WWE is not consistent. It is more appropriate to counsel the WWE and her partner in terms of minimizing risk. This will include a discussion of increased risk with multiple AEDs or high AED levels and the potential contributions of heredity and seizure occurrence during pregnancy to the development of birth defects.

Vitamin $K$. Hemorrhagic disease of the newborn (HDN) was described over a century ago. The relation between HDN and vitamin $\mathrm{K}$ deficiency and the protective effect of administering vitamin $K$ to the neonate have been clearly demonstrated. The American Academy of Pediatrics Committee on Nutrition recommended the administration of vitamin $\mathrm{K}$ prophylaxis to newborns in 1961, and this remains the standard of care for prevention of HDN. ${ }^{72} \mathrm{HDN}$ typically occurs between 2 and 7 days of age, although early (under 24 hours) and delayed (over 1 month) forms are described. Exclusive breast-feeding, concurrent illness, and omission of neonatal administration of vitamin $K$ have been implicated in the delayed form. The maternal use of hepatic-enzymeinducing drugs, including AEDs, plays a role in the 
early form. Early HDN was defined as a syndrome in 1970 , and has been reported in newborns exposed in utero to phenobarbital, primidone, phenytoin, carbamazepine, diazepam, and ethosuximide..$^{73}$ Vitamin $K$ deficiency, reduced levels of vitamin $K$ dependent clotting factors, and prolonged prothrombin and partial thromboplastin times are seen in neonates of WWE taking AEDs. ${ }^{73,74}$

Prenatal administration of oral vitamin $\mathrm{K}$ to the pregnant WWE taking AEDs has been recommended for many years as prevention of early HDN. The potential for placental transfer of vitamin $\mathrm{K}$ to the fetus has been questioned, however. In a study of normal pregnant women, Shearer et al. found that newborn plasma vitamin $K_{1}$ levels were undetectable in the face of normal maternal levels. ${ }^{75}$ The administration of intravenous vitamin $K_{1}$ to six mothers 11 to 47 minutes before delivery resulted in detectable cord plasma levels in four of six neonates. This group postulated that vitamin $K_{1}$ does not cross the placenta readily or that fetal plasma uptake is poor due to low levels of lipoprotein in cord plasma. Sann et al., however, found comparable vitamin $\mathrm{K}_{1}$ concentrations in all but one of 27 mother-infant pairs in which the maternal level was in the control range. ${ }^{76}$ More recently, prenatal vitamin $\mathrm{K}_{1}$ supplementation for WWE in the last month of pregnancy at $10 \mathrm{mg} /$ day was shown to suppress the appearance of nonfunctional procoagulants or protein induced by vitamin $\mathrm{K}$ absence for factor II (PIVKA-II), which reflect vitamin $\mathrm{K}$ deficiency and potential coagulopathy. ${ }^{77}$ Although placental transfer of vitamin $\mathrm{K}$ to the fetus may be inefficient, sufficient maternal supplementation appears to modify plasma abnormalities related to vitamin $\mathrm{K}$ deficiency in the newborn.

Outcome studies are required to confirm the clinical usefulness of maternal vitamin $\mathrm{K}$ supplementation for prevention of HDN in neonates exposed prenatally to AEDs. The practice of prenatal supplementation for WWE should not supplant the recommendation of the American Academy of Pediatrics that all neonates receive vitamin $K_{1}$ at birth.

Breast-feeding. Health benefits shown to accrue for breast-fed infants include prevention of diarrheal and respiratory illness and possibly reduced risk of some chronic diseases later in life. These advantages may be most important for infants in underdeveloped countries, but are documented for infants in industrialized nations as well. ${ }^{78}$ AEDs are known to appear in breast milk in levels inversely proportional to their degree of maternal serum protein binding. Breast milk levels of all AEDs in common use have been reported (table). ${ }^{79-82}$ Lamotrigine has recently been measured in the cord blood and serum of an infant whose mother was treated with this AED during pregnancy and lactation. Levels comparable to those seen in patients treated with this drug were seen, although no adverse effects were identified. ${ }^{83}$ Although AED concentrations in breast milk may be low, reduced neonatal serum protein binding and slower rates of hepatic metabolism may result in
Table Concentration of antiepileptic drugs in breast milk expressed as percentage of maternal plasma concentration

\begin{tabular}{lcl}
\hline Antiepileptic drug & Breast milk & Reported adverse effect \\
\hline Carbamazepine $^{81}$ & $41 \pm 16.8$ & \\
Ethosuximide $^{81}$ & $94 \pm 6$ & \\
Lamotrigine $^{83}$ & $\begin{array}{c}65(48 \mathrm{~h} \\
\text { postpartum) }\end{array}$ & \\
& $36.1 \pm 19.5$ & Sedation \\
Phenobarbital $^{81}$ & $18.6 \pm 15.7$ & Methemoglobinemia \\
Phenytoin $^{81}$ & $70.5 \pm 29.2$ & Sedation, feeding difficulties \\
Primidone $^{81}$ & $2.7 \pm 1.5$ & Thrombocytopenic purpura \\
Valproate $^{80}$ & & \\
\hline
\end{tabular}

serum levels in the therapeutic range. Infant sedation and feeding difficulties have been reported in breast-fed infants of mothers taking phenobarbital and primidone. ${ }^{82}$ Rare case reports of hematologic or hepatic abnormalities occurring in breast-fed infants of WWE taking AEDs have not established a causal relationship. The long-term growth and development of breast-fed infants of WWE taking AEDs has not been studied.

AED use by WWE does not constitute an absolute or automatic contraindication to breast-feeding for their infants. WWE who choose to breast-feed their newborns should be supported in their decision and counseled regarding the benefits of this form of infant nutrition. They should be appraised of the potential for infant sedation or feeding difficulties if taking sedating AEDs and of uncertainty regarding the effect of AEDs on newborn growth and development. The potential for hematologic or hepatic toxicity in breast-fed infants of WWE taking AEDs appears to be small.

Conclusion. There is a pressing need for welldesigned studies addressing every health issue for WWE reviewed, especially in light of the availability of several new AEDs. Critical areas for future study are outlined in the accompanying summary statement. ${ }^{4}$ Physician education surrounding management issues for WWE is required at all levels of training and practice, and evidence-based practice parameters provide a potentially valuable tool in this education process.

\section{References}

1. Hauser WA, Annegers JF, Rocea WA. Descriptive epidemiology of epilepsy: contributions of population-based studies from Rochester, Minnesota. Mayo Clin Proc 1996;71:576-586.

2. Krauss GL, Brandt J, Campbell M, Plate C, Summerfield M. Antiepileptic medication and oral contraceptive interactions: a national survey of neurologists and obstetricians. Neurology 1996;46:1534-1539.

3. Russell AJ, Macpherson H, Cairnie V, Brodie MJ. The care of pregnant women with epilepsy-a survey of obstetricians in Scotland. Seizure 1996;5:271-277.

4. Quality Standards Subcommittee of the American Academy of Neurology. Practice Parameter: Management issues for women with epilepsy (summary statement). Neurology 1998; $51: 944-948$ 
5. Logothetis J, Harner R. Electrocortical activation by estrogens. Neurology 1960;3:290-297.

6. Stitt SL, Kinnard WJ. The effect of certain progestins and estrogens on the threshold of electrically induced seizure patterns. Neurology 1968;18:213-216.

7. Nicoletti F, Speciale C, Sortino MA, et al. Comparative effects of estradiol benzoate, the antiestrogen clomiphene citrate, and the progestin medroxyprogesterone acetate on kainic acidinduced seizures in male and female rats. Eipilepsia 1985;26: 252-257.

8. Hom AC, Buterbaugh GG. Estrogen alters the acquisition of seizures kindled by repeated amygdala stimulation or pentylenetetrazol administration in ovariectomized female rats. Epilepsia 1986;27:103-108.

9. Logothetis J, Harner R, Morrell F, Torres F. The role of estrogens in catemenial exacerbation of epilepsy. Neurology 1958;9: $352-360$.

10. Backstrom T, Zetterlund B, Blom S, Romano M. Effects of intravenous progesterone infusions on the epileptic discharge frequency in women with partial epilepsy. Acta Neurol Scand 1984;69:240-248.

11. Duncan S, Read CL, Brodie MJ. How common is catamenial epilepsy? Epilepsia 1993;34:827-831.

12. Rosciscewska D. Analysis of seizure dispersion during menstrual cycle in women with epilepsy. Monogr Neurol Sci. Basel: Karger, 1980;5:280-284.

13. Tauboll E, Lundervold A, Gjerstad L. Temporal distribution of seizures in epilepsy. Epilepsy Res 1991;8:15:-165.

14. Backstrom T, Jorpes P. Serum phenytoin, phenobarbital, carbamazepine, albumin; and plasma estradiol, progesterone concentrations during the menstrual cycle in women with epilepsy. Acta Neurol Scand 1979;59:63-71.

15. Cummings LN, Giudice L, Morrell MJ. Ovulatory function in epilepsy. Epilepsia 1995;36:355-359.

16. Bilo L, Meo R, Valentino R, et al. Abnormal pattern of luteinizing hormone pulsatility in women with epilepsy. Fertil Steril 1991;55:705-711.

17. Isojarvi JIT, Laatikainen TJ, Pakarinen AJ, Juntunen KTS Myllylä VV. Polycystic ovaries and hyperandrogenism in women taking valproate for epilepsy. N Engl J Med 1993;329: $1383-1388$

18. Drislane FW, Coleman AE, Schomer DL, et al. Altered pulsatile secretion of luteinizing hormone in women with epilepsy. Neurology 1994:44:306-310.

19. Dansky LV, Andermann E, Andermann F. Marriage and fertility in epileptic patients. Epilepsia 1980;21:261-271.

20. Webber MP, Hauser WA, Ottman R, Annegers JF. Fertility in persons with epilepsy: 1935-1974. Epilepsia 1.986;27:746-752.

21. Herzog AG, Seibel MM, Schomer DL, Vaitukaitis JL, Geschwind N. Reproductive endocrine disorders in women with partial seizures of temporal lobe origin. Arch Neurol 1986;43:341-345.

22. Morrell MJ, Sperling MR, Stecker M, Dichter MA. Sexual dysfunction in partial epilepsy: a deficit in physiological sexual arousal. Neurology 1994;44:243-247.

23. Morrell MJ, Guldner GT. Self-reported sexual function and sexual arousability in women with epilepsy. Epilepsia 1996; 37:1204-1210.

24. Back DJ, Bates $M$, Bowden $A$, et al. The interaction of phenobarbital and other anticonvulsants with oral contraceptive steroid therapy. Contraception 1980;22:495-503.

25. Crawford P, Chadwick, DJ, Martin C, et al. The interaction of phenytoin and carbamazepine with combined oral contraceptive steroids. Br J Clin Pharmacol 1990;30:892-896.

26. Rosenfeld WE, Doose DR, Walker SA, Nayak RD. Effect of topiramate on the pharmacokinetics of an oral contraceptive containing norethindrone and ethinyl estradiol in patients with epilepsy. Epilepsia 1997;38:317-323.

27. Haukkamaa M. Contraception by Norplant subdermal capsules is not reliable in epileptic patients on anticonvulsant therapy. Contraception 1986;33:559-565.

28. Gough H, Goggin T, Bissessar A, et al. A comparative study of the relative influence of different anticonvulsant drugs, UV exposure and diet on vitamin $\mathrm{D}$ and calciurn metabolism in out-patients with epilepsy. Q J Med 1986;230:569-577.

29. Valimaki $M$, Tiihoonen $M$, Laitinen $K$, et al. Bone mineral density measured by dual-energy $x$-ray absorptiometry and novel markers of bone formation and resorption in patients on antiepileptic drugs. J Bone Miner Res 1994;9:631-637.

30. Sheth R, Wesolowski C, Jacob J, et al. Effect of carbamazepine and valproate on bone mineral density. J Pediatr 1995; 127:256-262.

31. Robert E, Guibaud P. Maternal valproic acid and congenital neural tube defects. Lancet 1982;11:937.

32. Lindhout D, Schmidt D. In utero exposure to valproate and neural tube defects. Lancet $1986 ; \mathrm{i}: 1392-1393$.

33. Rosa F. Spina bifida in infants of women treated with carbamazepine during pregnancy. N Engl J Med 1991;324:674-677.

34. Kallen AJ. Maternal carbamazepine and infant spina bifida Reprod Toxicol 1994:8:203-205.

35. Milunsky A, Jick H, Jick SS, et al. Multivitamin/folic acid supplementation in early pregnancy reduces the prevalence of neural tube defects. JAMA 1989;262:2847-2852.

36. MRC Vitamin Study Research Group. Prevention of neural tube defects: results of the Medical Research Council Vitamin Study. Lancet 1991;338:131-137.

37. Czeizel AE, Dudas I. Prevention of the first occurrence of neural tube defects by periconceptional vitamin supplementation. N Engl J Med 1992;327:1832-1835.

38. Centers for Disease Control and Prevention. Recommendations for the use of folic acid to reduce the number of cases of spina bifida and other neural tube defects. MMWR 1992; 41(no. RR-14):1-7.

39. Daily Le, Kirke PN, Mollow A, Weir Dg, Scott JM. Folate levels and neural tube defects: implications for treatment. JAMA 1995;27:1698-1702.

40. Van Allen MI, Fraser FC, Dallaire L, et al. Recommendations on the use of folic acid supplementation to prevent the recurrence of neural tube defects. Can Med Assoc J 1993;149:12391243.

41. Grimes DA. Unplanned pregnancies in the US. Obstet Gynecol 1986;67:438-442.

42. Nelson KB, Ellenberg JH. Maternal seizure disorder, outcome of pregnancy, and neurologic abnormalities in the children. Neurology 1982;32:1247-1254.

43. Yerby MS, Cawthon L. Mortality rates in infants of mothers with epilepsy. Ann Neurol 1994;36:330. Abstract.

44. Martin PJ, Millac PAH. Pregnancy, epilepsy, management and outcome: a 10-year perspective. Seizure 1993;2:277-280.

45. Schmidt D, Canger R, Avanzini G, et al. Change of seizure frequency in pregnant epileptic women. $J$ Neurol Neurosurg Psychiatry 1983;46:751-755.

46. Gjerde IO, Strandjord RE, Ulstein M. The course of epilepsy during pregnancy: a study of 78 cases. Acta Neurol Scand 1988;78:198-205.

47. Tomson T, Lindbom U, Ekqvist B, Sundqvist A. Epilepsy and pregnancy: a prospective study of seizure control in relation to free and total plasma concentrations of carbamazepine and phenytoin. Epilepsia 1994;35:122-130.

48. Knight AH, Rhind EG. Epilepsy and pregnancy: a study of 153 pregnancies in 59 patients. Epilepsia 1975;16:99-110.

49. Teramo K, Hiilesmaa V, Bardy A, Saarikoski S. Fetal heart rate during a maternal grand mal epileptic seizure. J Perinat Med 1979;7:3-6.

50. Minkoff H, Schaffer RM, Delke I, Grunebaum A. Diagnosis of intracranial hemorrhage in utero after a maternal seizure. Obstet Gynecol 1985;65:22S-24S.

51. Yerby MS, Leppik I. Epilepsy and the outcome of pregnancy. J Epilepsy 1990;3:193-199.

52. Speidel BD, Meadow SR. Maternal epilepsy and abnormalities of the fetus and newborn. Lancet 1972;308:839-843.

53. Nakane Y, Okuma T, Takahashi R, et al. Multi-institutional study on the teratogenicity and fetal toxicity of antiepileptic drugs: a report of a collaborative study group in Japan. Epilepsia 1980;21:663-680

54. Lindhout $D$, Hoppener $R$, Meinardi $H$. Teratogenicity of antiepileptic drug combinations with special emphasis on epoxidation (of carbamazepine). Epilepsia 1984;25:77-83.

55. Kelly TE, Edwards P, Rein M, Miller JQ, Dreifuss FE. Teratogenicity of anticonvulsant drugs. II: A prospective trial. Am J Med Genet 1984;19:435-443.

56. Kaneko S, Otani K, Fukushima J, et al. Teratogenicity of antiepileptic drugs: analysis of possible risk factors. Epilepsia 1988;29:459-467.

57. Battino D, Binelii S, Caccamo ML, et al. Malformations in 
offspring of 305 epileptic women: a prospective study. Acta Neurol Scand 1992;85:204-207.

58. Jick SS, Terris B. Anticonvulsants and congenital malformations. Pharmacotherapy 1997;17:561-564.

59. Waters CH, Belai Y, Gott PS, Shen P, Giorgio CM. Outcomes of pregnancy associated with antiepileptic drugs. Arch Neurol 1994;51:250-253.

60. King PB, Lie RT, Irgens LM. Spina bifida and cleft lip among newborns of Norwegian women with epilepsy: changes related to the use of anticonvulsants. Am J Public Health 1996;86 $1454-1456$.

61. Lindhout D, Meinardi $H$, Meijer WA, Nau H. Antiepileptic drugs and teratogenesis in two consecutive cohorts: changes in prescription policy paralleled by changes in pattern of malformations. Neurology 1992;42(suppl 5):94-110.

62. Jones KL, Lacro RV, Johnson KA, Adams J. Pattern of malformations in the children of women treated with carbamazepine during pregnancy. N Engl J Med 1989;320:1661-1667.

63. Gaily E, Granstrom M-L, Hiilesmaa V, Bardy A. Minor anomalies in offspring of epileptic mothers. J Pediatr 1988;112: $520-529$.

64. Nulman I, Scolnik D, Chitayat D, Farkas L, Koren G. Findings in children exposed in utero to phenytoin and carbamaz epine monotherapy: independent effects of epilepsy and medications. Am J Med Genet 1997;68:18-24.

65. Steegers-Theunissen RPM, Renier WO, Borm GF, et al. Factors influencing the risk of abnormal pregnancy outcome in epileptic women: a multicentre prospective study. Epilepsy Res 1994;18:261-269.

66. Gaily E, Kantola-Scorsa E, Granstrom M-L. Intelligence of children of epileptic mothers. J Pediatr 1988;113:677-684

67. Scolnik D, Nulman I, Rovet $J$, et al. Neurodevelopment of children exposed in utero to phenytoin and carbamazepine monotherapy. JAMA 1994;271:767-770.

68. Losche G, Steinhausen H-C, Koch S, Helge H. The psychological development of children of epileptic parents. II. The differential impact of intrauterine exposure to anticonvulsant drugs and further influential factors. Acta Paediatr 1994;83: 961-966.

69. Strickler SM, Dansky LV, Miller MA, et al. Genetic predisposition to phenytoin-induced birth defects. Lancet 1985;2:746749 .

70. Buehler BA, Delimont D, Van Waes M, Finnell RH. Prenatal prediction of risk of the fetal hydantoin syndrome. N Engl J Med 1990;322:1567-1572.

71. Meyer JG. The teratological effects of anticonvulsants and the effects on pregnancy and birth. Eur Neurol 1973;10:179-190.
72. Committee on Nutrition of the American Academy of Pediatrics. Vitamin K compounds and their water soluble analogues: use in therapy and prophylaxis in pediatrics. Pediatrics 1961; 28:501-507.

73. Mountain KR, Hirsh J, Gallus AS. Maternal coagulation defect due to anticonvulsant treatment in pregnancy. Lancet $1970 ; 1: 265-268$

74. Cornelissen M, Steegers-Theunissen, Kollee L, et al. Increased incidence of neonatal vitamin $\mathrm{K}$ deficiency resulting from maternal anticonvulsant therapy. Am J Obstet Gynecol 1993;168:923-928.

75. Shearer MJ, Barkhan P, Rahim S, Stimmler L. Plasma vita$\min K_{1}$ in mothers and their newborn babies. Lancet 1982;2: $460-463$.

76. Sann $L$, Leclercq $M$, Troncy J, et al. Serum vitamin $K_{1}$ concentration and vitamin $\mathrm{K}$-dependent clotting factor activity in maternal and fetal cord blood. Am J Obstet Gynecol 1985;153: 771-774

77. Cornelissen M, Steegers-Theunissen, Kollee L, et al. Supplementation of vitamin $\mathrm{K}$ in pregnant women receiving anticon vulsant therapy prevents neonatal vitamin $\mathrm{K}$ deficiency. Am $J$ Obstet Gynecol 1993;168:884-888.

78. Cunningham AS, Jelliffe DB, Jelliffe EFP. Breast-feeding and health in the 1980s: a global epidemiologic review. J Pediatr 1991;118:659-665.

79. Kaneko $\mathrm{S}$, Sato T, Suzuki $\mathrm{K}$. The levels of anticonvulsants in breast milk. Br J Clin Pharmacol 1979;7:624-626.

80. Nau H, Rating D, Koch S, Hauser I, Helge H. Valproic acid and its metabolites: placental transfer, neonatal pharmacokinetics, transfer via mother's milk and clinical status in neonates of epileptic mothers. J Pharmacol Exp Ther 1981;219: $768-777$.

81. Kaneko S, Suzuki K, Sato T, Ogawa Y, Nomura Y. The problems of antiepileptic medication in the neonatal period: is breast-feeding advisable? In: Janz D, Bossi L, Dam M, Helge H, Richens A, Schmidt D, eds. Epilepsy, pregnancy and the child. New York: Raven Press, 1982:343-348.

82. Kuhnz W, Koch S, Helge H, Nau H. Primidone and phenobarbital during lactation period in epileptic women: total and free drug serum levels in the nursed infants and their effects on neonatal behavior. Dev Pharmacol Ther 1988;11:147-154.

83. Rambeck B, Kurlemann G, Stodieck SRG, May TW, Jurgens U. Concentrations of lamotrigine in a mother on lamotrigine treatment and her newborn child. Eur J Clin Pharmacol 1997; $51: 481-484$ 


\section{Neurology}

\section{Management issues for women with epilepsy: A review of the literature}

C. A. Zahn, M. J. Morrell, S. D. Collins, et al.

Neurology 1998;51;949-956

DOI 10.1212/WNL.51.4.949

\section{This information is current as of October 1,1998}

\section{Updated Information \& \\ Services}

\section{References}

Citations

Permissions \& Licensing

Reprints including high resolution figures, can be found at: http://n.neurology.org/content/51/4/949.full

This article cites 79 articles, 3 of which you can access for free at: http://n.neurology.org/content/51/4/949.full\#ref-list-1

This article has been cited by 8 HighWire-hosted articles: http://n.neurology.org/content/51/4/949.full\#\#otherarticles

Information about reproducing this article in parts (figures,tables) or in its entirety can be found online at:

http://www.neurology.org/about/about_the_journal\#permissions

Information about ordering reprints can be found online: http://n.neurology.org/subscribers/advertise

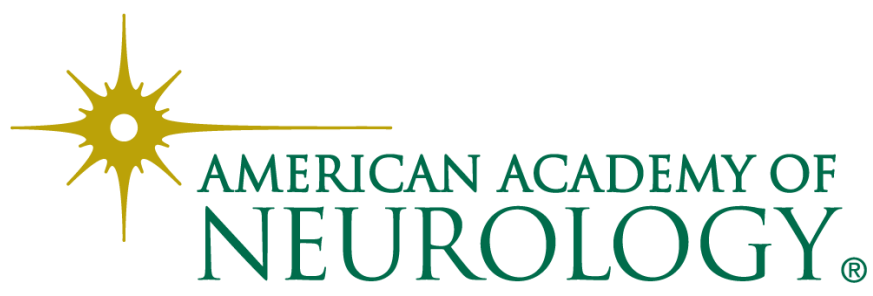

